\title{
Unexpected Tricovalent Binding Mode of Boronic Acids within the Active Site of a Penicillin-Binding Protein
}

\author{
Astrid Zervosen, ${ }^{\dagger}$ Raphael Herman, ${ }^{\ddagger}$ Frédéric Kerff, ${ }^{\ddagger}$ Alexandre Herman, ${ }^{\dagger}$ André Bouillez, ${ }^{\dagger}$ Fabio Prati, ${ }^{\S}$ \\ R. F. Pratt, ${ }^{\perp}$ Jean-Marie Frère, $^{\neq}$Bernard Joris, $^{\ddagger}$ André Luxen, ${ }^{\dagger}$ Paulette Charlier, ${ }^{\ddagger}$ and Eric Sauvage ${ }^{*, \neq}$ \\ ${ }^{\dagger}$ Centre de Recherches du Cyclotron and ${ }^{\ddagger}$ Centre d’Ingénierie des Protéines, Université de Liège, B-4000 Sart Tilman, Liège, Belgium \\ ${ }_{\S}^{\S}$ Department of Chemistry, University of Modena and Reggio Emilia, via Campi 183, 41125 Modena, Italy \\ ${ }^{\perp}$ Department of Chemistry, Wesleyan University, Middletown, Connecticut 06459, United States
}

Supporting Information

\begin{abstract}
Boronic acids bearing appropriate side chains are good inhibitors of serine amidohydrolases. The boron usually adopts a tetrahedral conformation, bound to the nucleophilic serine of the active site and mimicking the transition state of the enzymatic reaction. We have solved the structures of complexes of a penicillin-binding protein, the DD-peptidase from Actinomadura sp. R39, with four amidomethylboronic acids (2,6-dimethoxybenzamidomethylboronic acid, phenylacetamidomethylboronic acid, 2-chlorobenzamidomethylboronic acid, and 2-nitrobenzamidomethylboronic acid) and the pinacol ester derived from phenylacetamidomethylboronic acid. We found that, in each case, the boron forms a tricovalent adduct with $\mathrm{O} \gamma$ of Ser49, Ser298, and the terminal amine group of Lys410, three key residues involved in the catalytic mechanism of penicillin-binding proteins. This represents the first tricovalent enzyme-inhibitor adducts observed by crystallography. In two of the five R39-

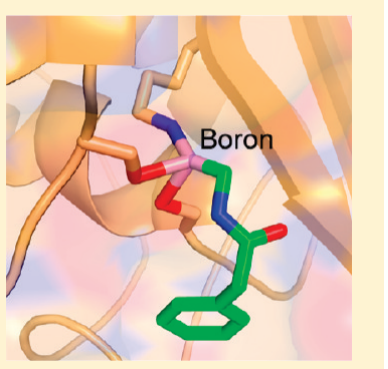
boronate structures, the boronic acid is found as a tricovalent adduct in two monomers of the asymmetric unit and as a monocovalent adduct with the active serine in the two remaining monomers of the asymmetric unit. Formation of the tricovalent complex from a classical monocovalent complex may involve rotation around the Ser $49 \mathrm{C} \alpha-\mathrm{C} \beta$ bond to place the boron in a position to interact with Ser298 and Lys410, and a twisting of the side-chain amide such that its carbonyl oxygen is able to hydrogen bond to the oxyanion hole $\mathrm{NH}$ of Thr413. Biphasic kinetics were observed in three of the five cases, and details of the reaction between R39 and 2,6-dimethoxybenzamidomethylboronic acid were studied. Observation of biphasic kinetics was not, however, thought to be correlated to formation of tricovalent complexes, assuming that the latter do form in solution. On the basis of the crystallographic and kinetic results, a reaction scheme for this unexpected inhibition by boronic acids is proposed.
\end{abstract}

\section{INTRODUCTION}

Penicillin-binding proteins (PBPs) are DD-peptidases involved in the late stages of peptidoglycan synthesis. ${ }^{1,2}$ Their natural substrate is the C-terminal D-Ala-D-Ala dipeptide of the stem pentapeptide necessary to cross-link the glycan chains of the peptidoglycan. ${ }^{3}$ A series of compounds, mainly containing variations on the theme of the $\beta$-lactam ring, have proven their efficacy as PBP inhibitors. For over 60 years, penicillins, cephalosporins, monobactams, and carbapenems have been used to combat all types of bacterial infections and continuously developed in response to the progressive bacterial resistance to $\beta$-lactam antibiotics.

Recent research has intensified the investigation of non- $\beta$-lactam inhibitors of PBPs, e.g., lactivicin, a bicyclic molecule with a $\gamma$-lactam/ $\gamma$-lactone ring structure, ${ }^{4,5}$ and shown that boronic acids represent potential inhibitors of PBPs. ${ }^{6-8}$ It has been known for a long time that serine amidohydrolases are inhibited by boronic acids, and structures of complexes between boronic acids and trypsin, chymotrypsin, subtilisin, elastase, $\alpha$-lytic protease, serine $\beta$-lactamases, prolyl tripeptidyl aminopeptidase, and hormone-processing protease have been described extensively. ${ }^{9-16}$ Most structures with boronic acids show the boron atom in a tetrahedral conformation, forming a covalent adduct with the catalytic serine, occupying the oxyanion hole, and underlining the analogy with the transition state of the catalytic process.

Escherichia coli PBP5 was the first PBP for which the crystallographic structure of a boronic acid complex was described. ${ }^{17}$ This structure has helped decipher the deacylation mechanism of penicillin-binding proteins. More recently, we described the structure of the DD-peptidase of Actinomadurax sp. R39 (R39) with an ethylboronic acid bearing the side chain of diaminopimelic acid, a characteristic amino acid of the peptidoglycan, providing a view of a transition state close to the one that is expected with the natural substrate of PBPs. ${ }^{6}$

Although almost all of these structures reveal the boron involved in a single dative covalent bond with the catalytic serine, other covalent complexes are possible between serine proteases and boronic acids. A dicovalent complex was first observed with $\gamma$-chymotrypsin and D-p-chlorophenyl- or D-1-naphthylboronic acids. ${ }^{15}$ Both compounds linked to Ser $195 \mathrm{O} \gamma$ and His $57 \mathrm{~N} \varepsilon 2$, two residues of the catalytic triad of $\gamma$-chymotrypsin. Likewise, dicovalent complexes with borate and benzylboronate linked to

Received: January 24, 2011 
<smiles>COc1cccc(OC)c1C(=O)NCB(O)O</smiles>

1<smiles>CC1(C)OC(C)(C)C(C)(C)O1</smiles>

2<smiles>O=C(Cc1ccccc1)NCB(O)O</smiles>

3<smiles>O=C(NCB(O)O)c1ccccc1Cl</smiles>

4<smiles>O=C(NCB(O)O)c1ccccc1[N+](=O)[O-]</smiles>

5

Figure 1. Structure of four amidomethylboronic acids and the pinacol ester crystallized in complexes with R39.

\section{Scheme 1}

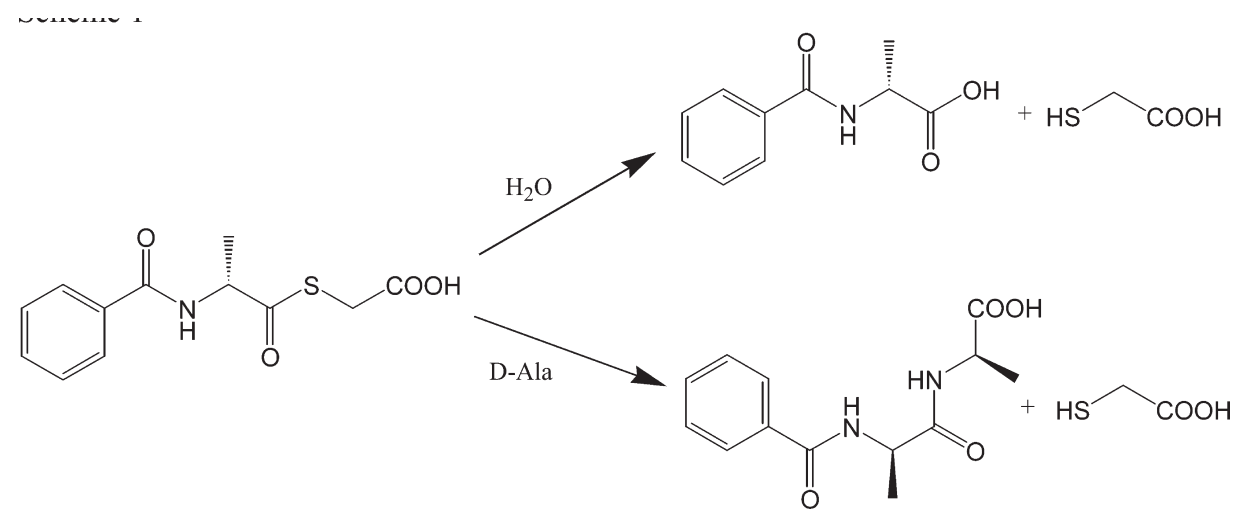

the catalytic serine and histidine were found in trypsin. ${ }^{12}$ Interestingly, the same authors found a dicovalent adduct linking the boronic acid to two serines at the surface of the protein. This adventitious boron binding showed that the distance between the hydroxyl oxygens of the serines had decreased to about $2 \AA$, much lower than the distance observed in unliganded structures, and thus the bidentate ligation of boronic acids relies on the ability of the hydroxyl oxygens to adopt a sufficiently close conformation. In these examples, the boron complex retained tetrahedral geometry and thus presumably remained anionic.

In the search for new inhibitors of PBPs, some boronic acids have recently been found to be good inhibitors of R39, a DD-peptidase suitable for structural characterization of PBP-inhibitor complexes. We have previously shown that $K_{\mathrm{i}}$ values in the nanomolar range could be achieved with ethylboronic acids, ${ }^{6,18}$ and this study was extended to methylboronic acids that had been shown to be good inhibitors of class A $\beta$-lactamases. We first tested 2,6-dimethoxybenzamidomethylboronic acid (1) and the pinacol ester of phenylacetamidomethylboronic acid (2), and, based on crystallographic and kinetic results, a series of arylamidomethylboronic acids with different aryl group substituents were synthesized and tested for soaking in R39 crystals. Structures of R39 in complex with 2-phenylacetamidomethylboronic acid (3), 2-chlorobenzamidomethylboronic acid (4), and 2-nitrobenzamidomethylboronic acid (5) were then solved. The structures and inhibition kinetics of R39 with the five compounds (Figure 1) are described, and the kinetics of 2,6-dimethoxybenzamidomethylboronic acid (1) are presented in detail. The unexpected feature of the results lies in the discovery in the crystal structures of unprecedented tricovalent boronate adducts at the DD-peptidase active site.

\section{MATERIALS AND METHODS}

Inhibition Kinetics of R39 by Boronic Acids. The synthesis of compounds $\mathbf{1}-\mathbf{5}$ will be described elsewhere. The thiolester S2d was prepared as described. ${ }^{19}$ All chemicals and reagents were purchased p.a. from commercial suppliers.

For R39 assays, the thiolester S2d was used as reporter substrate in the presence of $\mathrm{D}$-alanine. Under these conditions, the thiolester is utilized by hydrolysis and transpeptidation pathways, both of which yield 2-mercaptoacetate (Scheme 1).

When compared to the kinetics of the hydrolysis pathway alone, the presence of D-alanine increases both the apparent $K_{\mathrm{m}}$ and $k_{\text {cat }}$ values, but $k_{\text {cat }} / K_{\mathrm{m}}$ remains unchanged. ${ }^{20} \mathrm{D}$-Ala was used in order to increase the overall rate $k_{\text {cat }}$ of the reaction. Apparent values of $k_{\text {cat }}=68 \mathrm{~s}^{-1}$ and $K_{\mathrm{m}}=0.17 \mathrm{mM}$ have been determined in the presence of $100 \mathrm{mM} \mathrm{D}-\mathrm{Ala}$. The values were $k_{\text {cat }}=6 \mathrm{~s}^{-1}$ and $K_{\mathrm{m}}=0.015 \mathrm{mM}$ in the absence of D-Ala. ${ }^{21}$ The $k_{\text {cat }} / K_{\mathrm{m}}$ ratio of $400000 \mathrm{M}^{-1} \mathrm{~s}^{-1}$ is thus independent of the presence of the acceptor. The symbols $K_{\mathrm{m}}$ and $k_{\text {cat }}$ are used in the following equations for apparent $K_{\mathrm{m}}$ and $k_{\text {cat }}$ values.

The activity of R39 toward the thiolester was determined spectrophotometrically in the presence of 5,5'-dithiobis-(2-nitrobenzoic acid) $\left(\mathrm{DTNB} ; \varepsilon_{412 \mathrm{~nm}}=13600 \mathrm{M}^{-1} \mathrm{~cm}^{-1}\right)$. The latter compound reacts with the thiol group of 2-mercaptoacetate, yielding the dianion of 5-mercapto2-nitrobenzoic acid, which has an absorption maximum at $412 \mathrm{~nm}$. Assays were conducted at $30{ }^{\circ} \mathrm{C}$ in $10 \mathrm{mM}$ sodium phosphate buffer with $100 \mathrm{mM} \mathrm{NaCl}$ at $\mathrm{pH} 7.2$ and containing $100 \mathrm{mM} \mathrm{D}$-alanine, $100 \mu \mathrm{M} \mathrm{S} 2 \mathrm{~d}$, $1 \mathrm{mM} \mathrm{DTNB}$, and various concentrations of boronic acids. R39 (0.5 nM) was added last. For compound 1, S2d utilization was followed by absorbance at $412 \mathrm{~nm}$ using a Uvikon 860 spectrophotometer linked to a microcomputer through an RS232 interface. Biphasic progress curves were observed (Figure $2 \mathrm{a}$ ). Once the time course was complete, $v_{0 \mathrm{i}} v_{\mathrm{s}}$, and $k$ values were determined by fitting the data to eq 5 by means of the program KINETICS. $^{22}$

Assuming a competitive inhibition, the dissociation constant $K_{\mathrm{i}}$ for the initial EI complex and the overall dissociation constant $K_{\mathrm{i}}^{*}$ can be obtained from eqs 1 and 2 .

$$
v_{0 \mathrm{i}}=\frac{V_{\max }[\mathrm{S}]}{[\mathrm{S}]+K_{\mathrm{m}}\left(1+[\mathrm{I}] / K_{\mathrm{i}}\right)}
$$



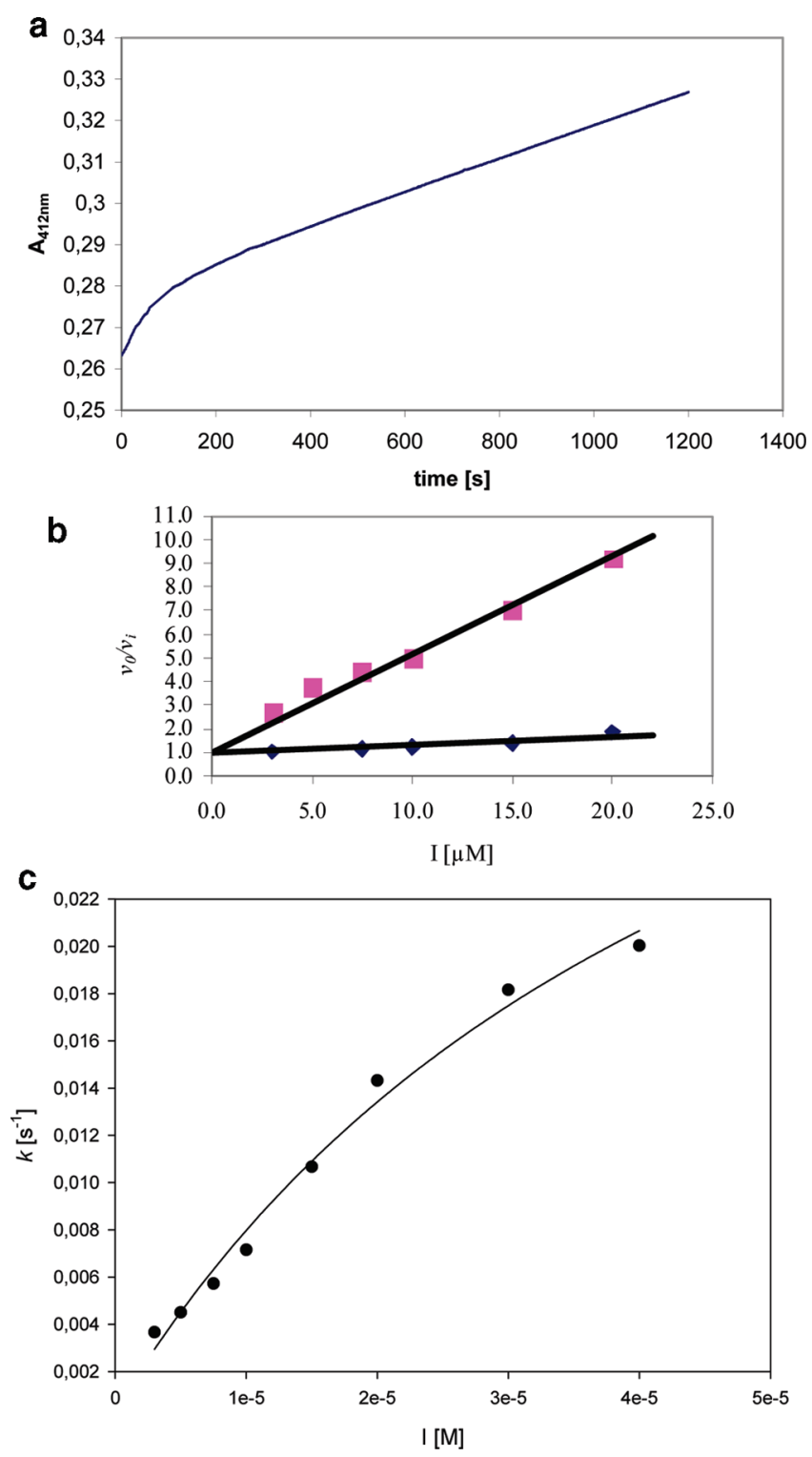

Figure 2. (a) Time-dependent inhibition of R39 by $\mathbf{1}$. A biphasic curve for the hydrolysis of S2d $(100 \mu \mathrm{M})$ by R39 in the presence of $30 \mu \mathrm{M} \mathbf{1}$ in $10 \mathrm{mM}$ sodium phosphate buffer with $100 \mathrm{mM} \mathrm{NaCl}, \mathrm{pH} 7.0$, and $100 \mathrm{mM}$ D-alanine at $30^{\circ} \mathrm{C}$. (b) Variation of the initial rate $v_{0} / \nu_{\mathrm{i}}=v_{0} / v_{0 \mathrm{i}}$ (blue diamonds) and the steady-state rate $v_{0} / \nu_{\mathrm{i}}=v_{0} / \nu_{\mathrm{s}}$ (pink squares) with the concentration of $\mathbf{1} . v_{0}$ is the initial rate in the absence of inhibitor. The points are experimental and the lines calculated via eqs 1 and 2 as described in the text. (c) Variation of the apparent first-order rate constant $k$ with concentration of $\mathbf{1}$. The points are experimental, and the line is calculated via eq 6 as described in the text.

$$
v_{\mathrm{s}}=\frac{V_{\max }[\mathrm{S}]}{[\mathrm{S}]+K_{\mathrm{m}}\left(1+[\mathrm{I}] / K_{\mathrm{i}}{ }^{*}\right)}
$$
$v_{0} / v_{\mathrm{i}}$ (where $v_{0}$ is the initial rate in the absence of inhibitor and $v_{\mathrm{i}}$ is $v_{0 \mathrm{i}}$ or $v_{\mathrm{s}}$ ) was plotted against [I] (Figure $2 \mathrm{~b}$ ), and the dissociation constants were calculated from the slope given by $K_{\mathrm{m}} /\left\{\left(K_{\mathrm{m}}+[\mathrm{S}]\right) K_{\mathrm{i}}\right\}$ or $K_{\mathrm{m}} /\left\{\left(K_{\mathrm{m}}+[\mathrm{S}]\right) K_{\mathrm{i}}^{*}\right\}$, respectively. The estimation of the constants was made under the following conditions: The concentration of the inhibitor I was more than 1000 times the enzyme concentration and could be regarded as constant. The substrate concentration was lower than the $K_{\mathrm{m}}$ value and corresponded to its initial value because substrate consumption was lower than $10 \%$.

The overall dissociation constant $K_{\mathrm{i}}^{*}$ is given by

$$
K_{\mathrm{i}}^{*}=\frac{K_{\mathrm{i}} k_{-2}}{k_{+2}+k_{-2}}=\frac{[\mathrm{E}][\mathrm{I}]}{[\mathrm{EI}]+\left[\mathrm{EI}{ }^{*}\right]}
$$

The ratio $k_{+2} / k_{-2}$ can then be obtained from

$$
\frac{k_{+2}}{k_{-2}}=\left(\frac{K_{\mathrm{i}}}{K_{\mathrm{i}}^{*}}-1\right)
$$

For compounds $\mathbf{2}-\mathbf{5}$, only steady-state rates, corresponding to the slower second phase of the reaction, were determined. Assays were conducted at $30{ }^{\circ} \mathrm{C}$ in $10 \mathrm{mM}$ sodium phosphate buffer with $100 \mathrm{mM}$ $\mathrm{NaCl}, \mathrm{pH} 7.2$, and $100 \mathrm{mM}$ D-alanine. R39 (7 nM) was mixed with various concentrations of boronic acids and incubated for $60 \mathrm{~min}$. Steady-state rates $v_{\mathrm{s}}$ were determined after the addition of $100 \mu \mathrm{M} \mathrm{S} 2 \mathrm{~d}$ and $1 \mathrm{mM}$ DTNB using microtiter 96-well plates and a Power Wave microtiter plate reader (Bio-Tek Instruments, Winooski, VT). The S2d substrate concentration was chosen to be close to the $K_{\mathrm{m}}$ value $\left(K_{\mathrm{m}}=0.17 \mathrm{mM}\right) . K_{\mathrm{i}}^{*}$ values were derived assuming a competitive pattern of inhibition and by plotting $v_{0} / v_{s}=f(I)$, where $v_{0}$ is the initial rate in the absence of inhibitor and $v_{\mathrm{s}}$ the steady-state rate in the presence of inhibitor. $K_{\mathrm{i}}^{*}$ values could be calculated from the slope of the resulting straight line given by $K_{\mathrm{m}} /\left\{\left(K_{\mathrm{m}}+[\mathrm{S}]\right) K_{\mathrm{i}}^{*}\right\}$. The rate of the nonenzymatic reaction of $S 2 d$ was always measured and subtracted.

R39 DD-Peptidase Crystallography. The R39 DD-peptidase was expressed and purified as described previously. ${ }^{23}$ Crystals were grown at $20{ }^{\circ} \mathrm{C}$ by hanging drop vapor diffusion. Crystals were obtained by mixing $2.5 \mu \mathrm{L}$ of a $25 \mathrm{mg} \mathrm{mL}^{-1}$ protein solution (also containing $5 \mathrm{mM}$ $\mathrm{MgCl}_{2}$ and $20 \mathrm{mM}$ Tris, $\mathrm{pH} 8$ ), $2 \mu \mathrm{L}$ of well solution (2.5 M ammonium sulfate and $0.1 \mathrm{M} \mathrm{MES}, \mathrm{pH} 6$ ), and $0.5 \mu \mathrm{L}$ of $0.1 \mathrm{M} \mathrm{CoCl}_{2}$ solution.

Crystals were grown in the presence of $0.1 \mathrm{M} \mathrm{2}$, and cocrystallization was refreshed by soaking the crystal in a solution consisting of $6 \mu \mathrm{L}$ of $3 \mathrm{M}$ ammonium sulfate and $0.1 \mathrm{M} \mathrm{MES}, \mathrm{pH} 6$, and $0.2 \mu \mathrm{L}$ of $0.1 \mathrm{M} 2$ for $30 \mathrm{~min}$ before data collection.

Crystals were soaked in a solution consisting of $4 \mu \mathrm{L}(6 \mu \mathrm{L}$ for compound 1) of $3 \mathrm{M}$ ammonium sulfate and 0.1 M MES, $\mathrm{pH} 6$, and $0.2 \mu \mathrm{L}$ of $1,3,4$, or 5 at a concentration of $0.1 \mathrm{M}$ before data collection $(285,30,160$, and $30 \mathrm{~min}$, respectively).

Data were collected on an ADSC Q315r CCD detector at a wavelength of $0.9763 \AA$ on beamline BM30A at the European Synchrotron Radiation Facility (ESRF, Grenoble, France). X-ray diffraction experiments were carried out under cryogenic conditions $(100 \mathrm{~K})$ after the crystals were transferred into $45 \%$ glycerol in $1.8 \mathrm{M}$ ammonium sulfate. Intensities were indexed and integrated using Mosflm. ${ }^{24}$ Data were scaled with SCALA of the CCP4 program suite. ${ }^{25}$ Refinement was carried out using REFMAC5, ${ }^{26} \mathrm{TLS}^{27}$ and Coot. ${ }^{28}$ The resolutions of the structures of the R39 DD-peptidase bound to the different boronic acids range between 2.2 and $3.1 \AA$, with $R_{\text {cryst }}$ and $R_{\text {free }}$ values around $19 \%$ and $24 \%$, respectively. Data statistics and refinement are summarized in Table 1. Coordinates and structure factors have been deposited at the Protein Data Bank with the accession numbers $2 y 5 r$ (1), 2y5o (2), $2 y 55$ (3), 2y4a (4), and 2y59 (5).

\section{RESULTS}

Kinetics. The boronic acids $\mathbf{1} \mathbf{- 5}$ were good inhibitors of the R39 DD-peptidase. Slow binding behavior was observed for the thiolester S2d was used as reporter substrate. The inhibition kinetics of 2,6-dimethoxybenzamidomethylboronic acid (1) was studied in detail. Figure 2a shows a biphasic curve of the inhibition of R39 in the presence of $30 \mu \mathrm{M} 1$. This curve can interaction between R39 and boronic acids 1, 4, and 5 when the 
Table 1. Data Collection and Refinement Statistics

\begin{tabular}{|c|c|c|c|c|c|}
\hline & \multicolumn{5}{|c|}{ crystal } \\
\hline & 1 & 2 & 3 & 4 & 5 \\
\hline PDB code & $2 y 5 r$ & $2 y 5 o$ & $2 \mathrm{y} 55$ & $2 y 4 a$ & $2 y 59$ \\
\hline \multicolumn{6}{|l|}{ Data Collection } \\
\hline \multirow[t]{2}{*}{ resolution range $(\AA)^{a}$} & $35.8-3.1$ & $34.7-2.00$ & $41.3-2.60$ & $46.1-2.7$ & $46.0-2.5$ \\
\hline & $(3.27-3.1)$ & $(2.11-2.00)$ & $(2.74-2.60)$ & $(2.85-2.7)$ & $(2.64-2.50)$ \\
\hline no. of unique reflections & 35205 & 134070 & 57773 & 53645 & 69863 \\
\hline$R_{\text {merge }}(\%)^{a, b}$ & $13.0(40.4)$ & $10.8(48.2)$ & $5.3(38.3)$ & $10.6(56.8)$ & $10.0(55.9)$ \\
\hline redundancy $^{a}$ & $3.4(3.3)$ & $3.6(3.6)$ & $3.2(3.0)$ & $5.4(5.4)$ & $5.4(5.4)$ \\
\hline completeness $(\%)^{a}$ & $95.9(94.3)$ & $99.5(99.0)$ & $92.7(83.8)$ & $97.7(97.1)$ & $99.8(100)$ \\
\hline$\langle I\rangle /\langle\sigma I\rangle^{a}$ & $9.7(2.5)$ & $11.0(2.5)$ & $12.6(2.7)$ & $15.1(2.8)$ & $15.1(2.9)$ \\
\hline \multicolumn{6}{|l|}{ Refinement } \\
\hline resolution range & $35.8-3.1$ & $34.6-2.0$ & $38.8-2.6$ & $46.1-2.7$ & $42.0-2.5$ \\
\hline no. of non-hydrogen atoms & 13538 & 13394 & 13801 & 13712 & 13988 \\
\hline no. of water molecules & 0 & 1954 & 250 & 162 & 424 \\
\hline$R_{\text {cryst }}(\%)$ & 20.4 & 17.8 & 19.4 & 18.7 & 19.5 \\
\hline$R_{\text {free }}(\%)$ & 24.4 & 22.5 & 26.2 & 22.5 & 25.4 \\
\hline \multicolumn{6}{|l|}{ Rms Deviations from Ideal } \\
\hline \multicolumn{6}{|l|}{ Stereochemistry } \\
\hline bond lengths $(\AA)$ & 0.015 & 0.010 & 0.013 & 0.012 & 0.014 \\
\hline bond angles $\left({ }^{\circ}\right)$ & 1.80 & 1.22 & 1.46 & 1.47 & 1.547 \\
\hline mean $B$ factor (all atoms) $\left(\AA^{2}\right)$ & 56.8 .0 & 18.1 & 64.5 & 47.5 & 39.5 \\
\hline mean $B$ factor (ligand) $\left(\AA^{2}\right)^{c}$ & 50.7 & 26.1 & 37.6 & $57.5 / 46.1$ & $29.3 / 42.0$ \\
\hline \multicolumn{6}{|l|}{ Ramachandran Plot } \\
\hline most favored region (\%) & 86.4 & 92.8 & 88.8 & 88.5 & 90.4 \\
\hline additionally allowed regions (\%) & 13.1 & 6.8 & 10.9 & 10.8 & 9.0 \\
\hline generously allowed regions (\%) & 0.5 & 0.3 & 0.3 & 0.7 & 0.6 \\
\hline disallowed regions (\%) & 0 & 0 & 0 & 0 & 0 \\
\hline
\end{tabular}

${ }^{a}$ Statistics for the highest resolution shell are given in parentheses. ${ }^{b} R_{\text {merge }}=\Sigma\left|I_{\mathrm{i}}-I_{\mathrm{m}}\right| / \Sigma I_{\mathrm{i}}$, where $I_{\mathrm{i}}$ is the intensity of the measured reflection and $I_{\mathrm{m}}$ is the mean intensity of all symmetry-related reflections. Values within parentheses are for the outer resolution shell. ${ }^{c}$ Monomer $\mathrm{B}$ (tricovalent adducts)/ monomer A (monocovalent adducts).

Scheme 2. Reaction Scheme for Two-Step Inhibition by Boronic Acids

$$
\mathrm{E}+\mathrm{I} \underset{K_{\mathrm{i}}}{\rightleftharpoons} \mathrm{EI} \underset{k_{-2}}{\stackrel{k_{2}}{\rightleftharpoons}} \mathrm{EI}^{*}
$$

be described by eq $5,^{29}$

$$
p=v_{\mathrm{s}} t+\left(v_{0 \mathrm{i}}-v_{\mathrm{s}}\right)\left(1-\mathrm{e}^{-k t}\right) / k
$$

where $p$ is the concentration of product at time $t$. The rates $v_{0 \mathrm{i}}$ and $v_{\mathrm{s}}$ are the initial and steady-state rates in the presence of inhibitor, respectively. The apparent first-order rate constant $k$ characterizes the transition to a constant steady-state rate. From curves in the presence of various inhibitor concentrations, $v_{0 \mathrm{i}}, v_{\mathrm{S}}$, and $k$ values were calculated. The decrease of $v_{0 \mathrm{i}}$ with increasing boronate concentrations pointed to a two-step mechanism of slow binding inhibition (Scheme 2).

The initial rate $v_{0 \mathrm{i}}$ and the steady-state rate $v_{\mathrm{s}}$ vary with the concentration of $\mathbf{1}$ as shown in Figure 2b. Assuming a competitive inhibition, the dissociation constant $K_{\mathrm{i}}$ for the initial EI
Table 2. $K_{i}^{*}$ Values of All Boronic Acids Calculated from Steady-State Rates $v_{s}$ after a $60 \mathrm{~min}$ Preincubation of the Enzyme with Various Inhibitor Concentrations in $10 \mathrm{mM}$ Sodium Phosphate Buffer with $100 \mathrm{mM} \mathrm{NaCl}, \mathrm{pH}$ 7.0, and $100 \mathrm{mM}$ Alanine at $30{ }^{\circ} \mathrm{C}$

$\begin{array}{cc}\text { boronic acid } & K_{\mathrm{i}}^{*}(\mu \mathrm{M}) \\ \mathbf{1} & 1.2 \pm 0.2 / 1.5 \pm 0.2^{a} \\ \mathbf{2} & 125 \pm 8 \\ \mathbf{3} & 134 \pm 16 \\ \mathbf{4} & 42 \pm 7 \\ \mathbf{5} & 0.36 \pm 0.06\end{array}$

${ }^{a} K_{\mathrm{i}}^{*}$ calculated from progressive inhibition curves.

complex and the overall dissociation constant $K_{\mathrm{i}}^{*}$, which takes account of both EI and $\mathrm{EI}^{*}$, can be obtained from eqs 1 and 2 (see Materials and Methods).

For $1, K_{\mathrm{i}}$ and $K_{\mathrm{i}}^{*}$ values of $18.8 \pm 7.5$ and $1.5 \pm 0.2 \mu \mathrm{M}$, respectively, were observed. The ratio $k_{+2} / k_{-2}$ was thus 12 , calculated by eq 4 . A progressive increase of the inhibition indicates that a rapid equilibrium precedes a rate-determining formation of the more stable enzyme inhibitor complex EI* (Scheme 2). The 
variation of the apparent first-order rate constant $k$ in the presence of various concentrations of $\mathbf{1}$ is shown in Figure $2 \mathrm{c}$ and can be described by eq 6 :

$$
k=k_{-2}+\frac{k_{+2}[\mathrm{I}]}{K_{\mathrm{i}}\left(1+[\mathrm{S}] / K_{\mathrm{m}}\right)+[\mathrm{I}]}
$$

The rate constant $k_{+2}=0.031 \pm 0.015 \mathrm{~s}^{-1}$ has been obtained by fitting the results shown in Figure $2 c$ to eq 6. On the same basis, the $k_{-2}$ value was highly inaccurate (the error was larger than the value). Consequently, an approximate value was deduced with the help of eq 4, yielding $k_{-2}=0.003 \pm 0.001 \mathrm{~s}^{-1}$.

Biphasic curves were also observed for $\mathbf{4}$ and $\mathbf{5}$ but not for 2 and 3 , at least under our assay conditions. $K_{i}^{*}$ values for all boronic acids were determined by measuring the steady-state rates $v_{\mathrm{s}}$ after a $60 \mathrm{~min}$ preincubation of the enzyme with various inhibitor concentrations at $30^{\circ} \mathrm{C}$ (Table 2). For 1 the $K_{\mathrm{i}}^{*}$ value obtained under these condition was $1.2 \mu \mathrm{M}$, a value similar to that obtained by analyzing progress curves as described above. Compound 2 had a higher dissociation constant than 1, 4, and 5. The dissociation constants of $\mathbf{2}$ and $\mathbf{3}$ were similar, showing that the pinacol moiety of $\mathbf{2}$ had no influence, probably due to a rapid hydrolysis to the free boronic acid 3 in dilute aqueous solution. It is not known, of course, whether the $K_{\mathrm{i}}^{*}$ value in any particular case refers to formation of a mono- or tricovalent complex or to a mixture of both (see Discussion).

A two-step mechanism of slow binding inhibition has been described for various boronic acids with $\beta$-lactamase I from Bacillus cereus $^{16}$ and for peptide boronic acids with serine proteases. ${ }^{30} \mathrm{On}$ the other hand, Crompton et al. ${ }^{16}$ and Kettner and Shenvi ${ }^{30}$ have described some boronic acids that, like 2 , show no slow binding behavior. For $\beta$-lactamases, biphasic inhibition could not be observed under manual mixing assay conditions. Crompton et al. therefore suggested that the two-step mechanism could be involved in many more cases of enzyme inhibition by boronate, even if the first was too fast to be directly observed.

In the present examples, biphasic curves were generally observed when the concentration of boronic acid exceeded its $K_{\mathrm{i}}$ value by more than 10 times (Figure $2 \mathrm{a}$ ). All assays with 2 and 3 were done at concentrations lower than $1 \mathrm{mM}$, and thus we cannot rule out that these compounds could also show biphasic curves at higher concentrations.

Crystallography. Overall structures. R39 is a low-molecularweight type-4 PBP with a structure similar to those of E. coli PBP4 and B. subtilis PBP4a. ${ }^{31,32}$ The asymmetric unit of R39 crystals contains four protein molecules. Although not preventing small ligands from acylating the enzyme, the lower part of the active site of monomers A/D is obstructed by the loop 175-178 of a symmetric molecule, whereas monomers $\mathrm{B}$ and $\mathrm{C}$ show a freely accessible active site. Moreover, as a result of the steric action of the symmetric molecule on strand $\beta 3$, the active site of monomers $\mathrm{A} / \mathrm{D}$ is slightly narrower than the active site of monomers $\mathrm{B} / \mathrm{C}$. The electron densities observed in the five crystals are generally well defined. The overall fold of the five complexes is similar to the previously reported R39 structure with root-mean-square (rms) deviations between the apo and complex structures lower than $0.5 \AA$ for the $466 \mathrm{C} \alpha$ atoms of R39 monomer A (PDB 1W79), ${ }^{33}$ and $\mathrm{rms}$ deviations lower than $0.5 \AA$ between the different monomers. In particular, there is no significant structural difference between free or ligand-occupied monomers.

A tricovalent adduct is observed in all monomers in the crystals of R39 with compounds 1 and 3, and in monomers B/C with 2, 4, and 5. A monocovalent adduct is also observed in monomers A/ $\mathrm{D}$ with compounds $\mathbf{4}$ and $\mathbf{5}$.

Tricovalent Adducts. Clear densities extending off the active serine side chain and connected to the catalytically important residues Ser298 and Lys410 appear identically in all monomers where a tricovalent adduct is formed (Figure $3 a-d, 6$ ).

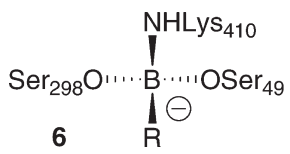

This density cannot arise from methylboronic acid linked only to the active serine in the monocovalent mode usually observed in serine proteases and $\beta$-lactamases, but it fits perfectly to the electron density when the boron atom is modeled tetrahedral and linked to Ser49, Ser298, and Lys410. The boron-oxygen and boron-nitrogen distances are 1.46 and $1.67 \AA$, respectively. The distance between the $\mathrm{O} \gamma$ atoms of Ser49 and Ser298 is about $2.1 \AA$, whereas in the apo enzyme this distance is $3.1 \AA$. Similar values have been observed by Transue et al. in structures of trypsin borate/benzylboronate complexes, where the closeness of the Ser164 and Ser167 side chains results from the dicovalent linkage of the boron with the two serines. ${ }^{12}$ In R39-methylboronic acid complexes, the closeness of the two serines results from a $90^{\circ}$ rotation of the Ser49 side chain and not from a motion of the hydroxyl group of Ser298. The distances between the O $\gamma$ of Ser49 and Ser298, and the $\mathrm{N} \varepsilon$ of Lys 52 are 2.8 and $3.0 \AA$, respectively.

The oxyanion hole is formed by the backbone $\mathrm{NH}$ groups of Thr413 and Ser49. In all tricovalent adduct structures described here, the amide oxygen of the boronic acid side chain is hydrogen bonded to Thr413N but not to Ser49N, and no water molecule could be observed in the oxyanion hole.

The conformations of $\mathbf{2}$ and $\mathbf{3}$ in the active site are identical, demonstrating the absence of influence of the pinacol on the structure of the complex (the structure of the tricovalent complex of $\mathbf{2}$ is not shown). The phenyl group of $\mathbf{2}$ inserts into the active site between Asn 300 and strand $\beta 3$, in a hydrophobic pocket made of residues Ala48, Gly348, Leu349, and Met414, that normally receives the side-chain methyl group of the penultimate D-alanine of the peptidoglycan stem peptide during trans/carboxypeptidation reaction. ${ }^{6}$ Because of the methoxy/chloro/nitro groups that decorate the phenyl groups in $\mathbf{1}, \mathbf{4}$, and $\mathbf{5}$, the latter could not adopt the orientation found with 2 or 3 and remain squeezed between the Asn 300 side chain and strand $\beta 3$. One methoxy group of 1 occupies the hydrophobic pocket described above. This hydrophobic interaction is probably favorable for the inhibition of R39 and could explain the 100 times lower $K_{\mathrm{i}}(1.2 \mu \mathrm{M})$ measured with 1 than with 2 or $3\left(K_{i}=125 \mu \mathrm{M}\right)$. As well, one nitro group oxygen of 5 lies in the oxyanion hole, and this stabilizing interaction could explain the very low $K_{\mathrm{i}}(0.36 \mu \mathrm{M})$ measured with 5. The chlorine atom of 4 appears much less efficient for inhibition. The small improvement of the $K_{\mathrm{i}}$ measured with $4(42 \mu \mathrm{M})$, compared to the one measured with 2 or $3(125 \mu \mathrm{M})$, is in agreement with the absence of strong interaction between the chlorine atom and the enzyme.

Monocovalent Adducts. A clear electron density extending off the active serine side chain (and not connected to residues Ser298 and Lys410) appears identically in monomers A/D of the complexes of R39 with 4 and $\mathbf{5}$ (Figure 3e,f). The ligands can be modeled with a single bond connecting the boron atom and the 
a)

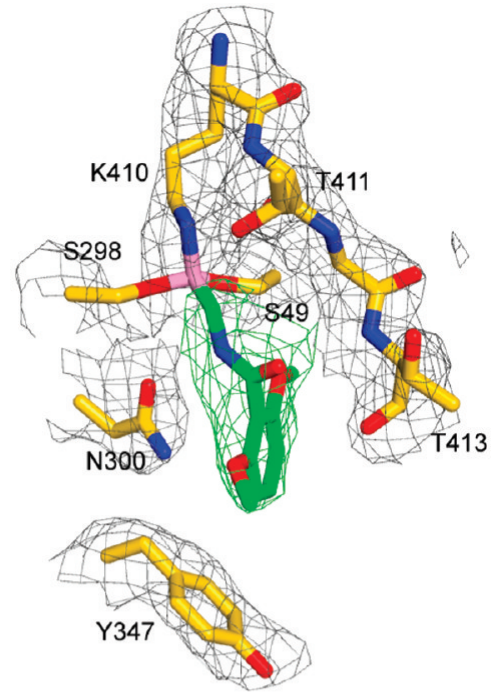

b)
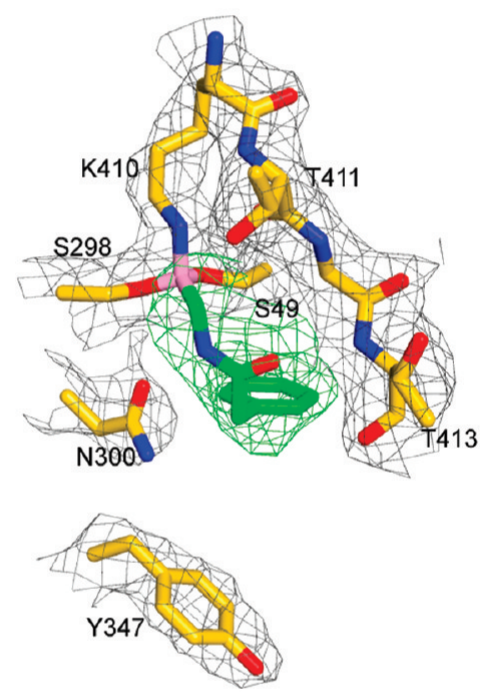

c)
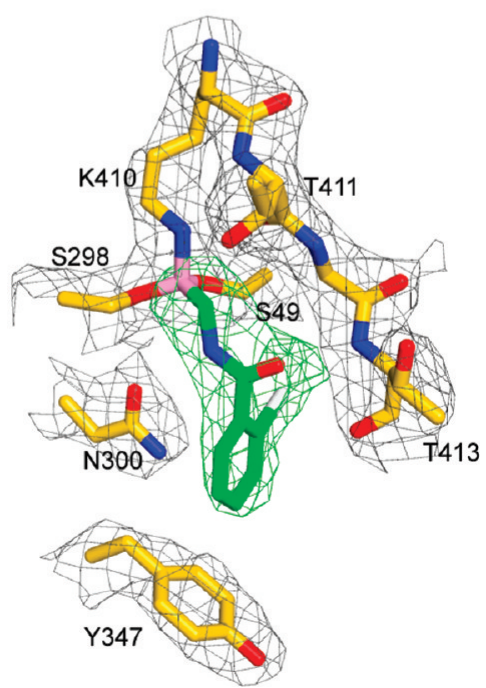
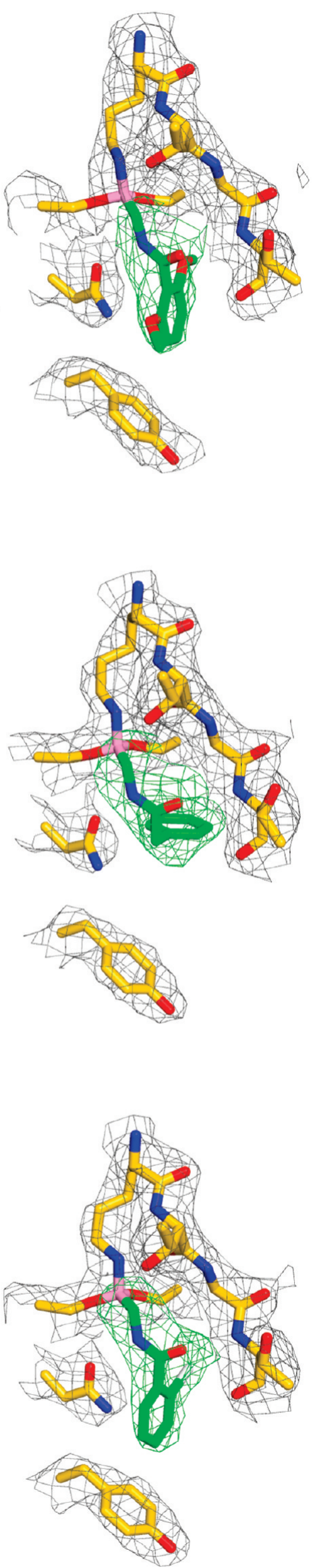

Figure 3. (Continued). 
d)

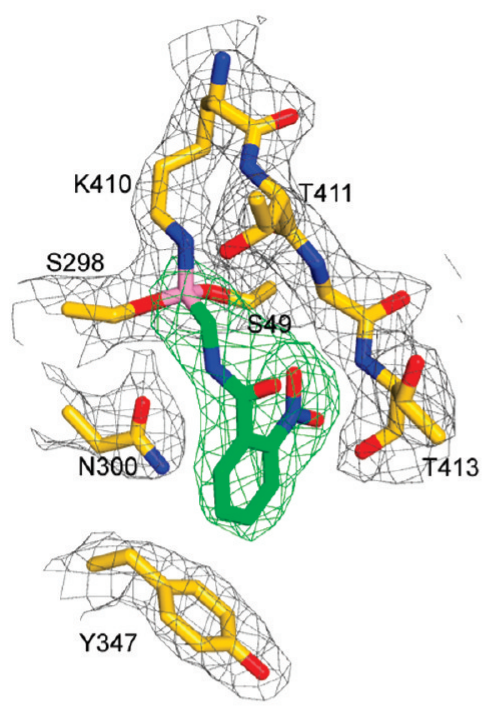

e)

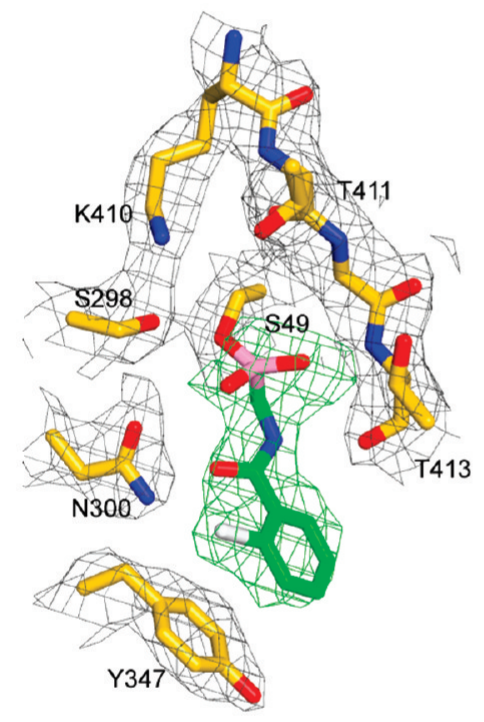

f)

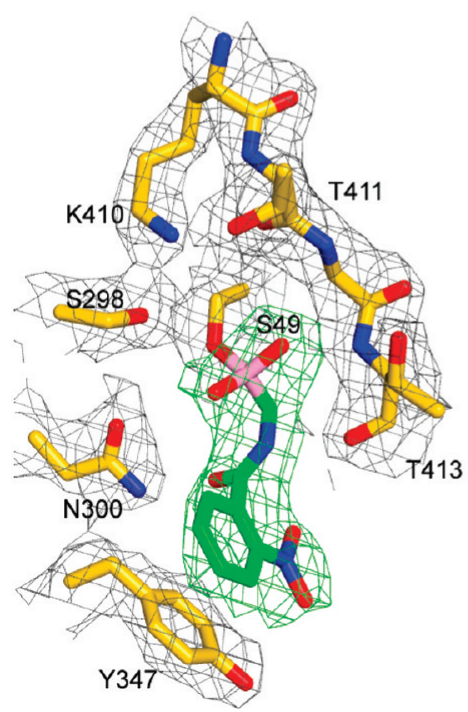

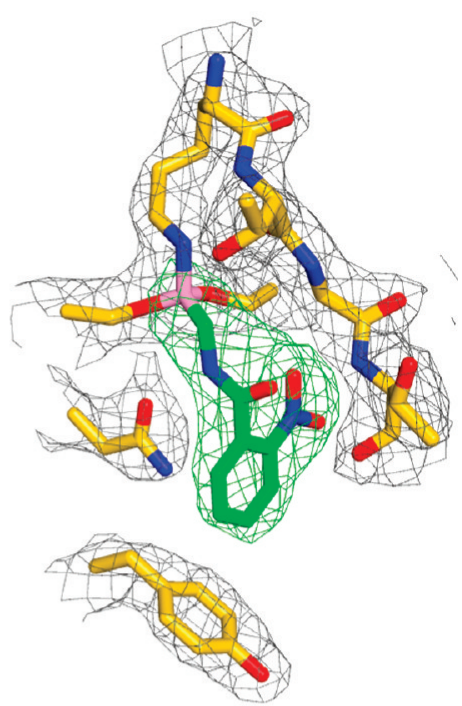
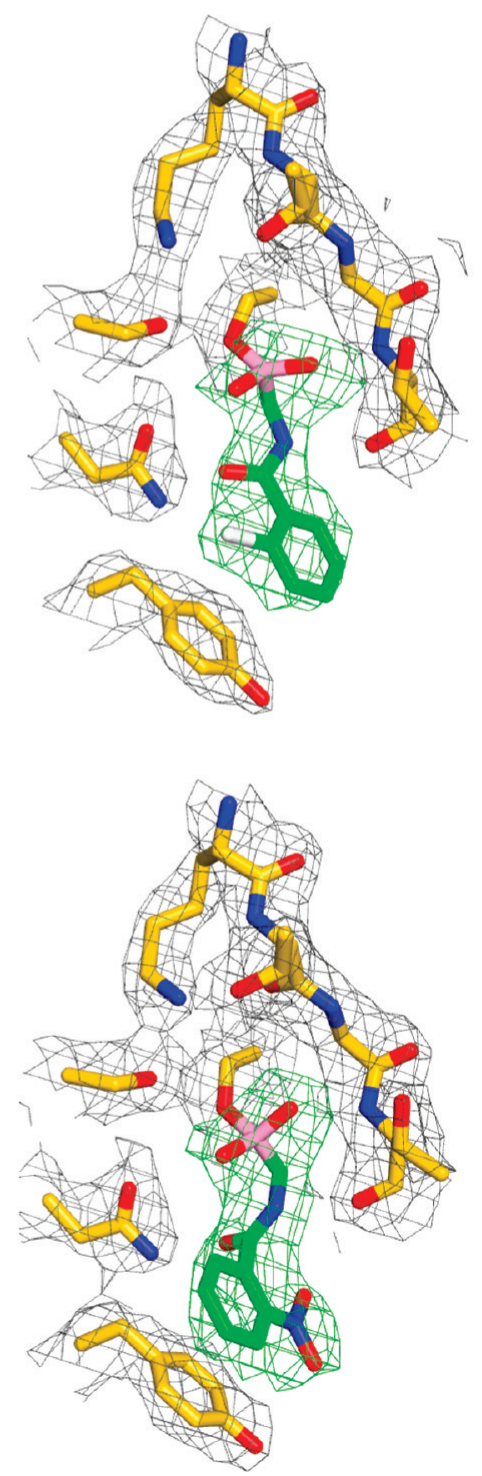

Figure 3. Stereoviews of initial $F_{\mathrm{o}}-F_{\mathrm{c}}$ electron densities around compounds 1, 3, 4, and $\mathbf{5}$ (green, contour level $2.5 \sigma$ ) and final $2 F_{\mathrm{o}}-F_{\mathrm{c}}$ maps around R39 residues (gray, contour level $1.0 \sigma$ ). (a-d) Tricovalent complexes in monomer B. (e,f) Monocovalent complexes of compounds 4 and 5 in monomer A. 


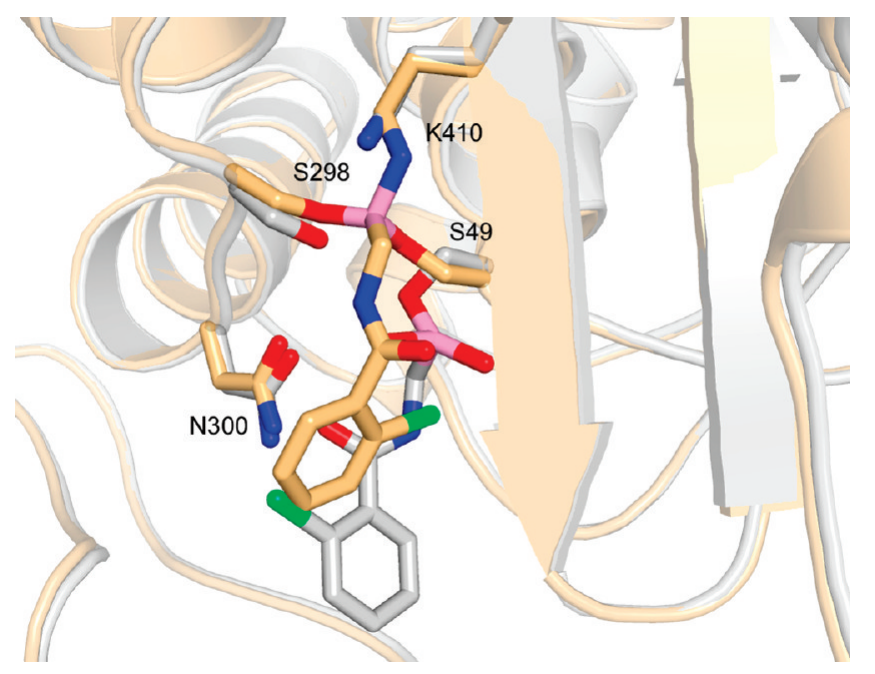

Figure 4. Overlap of monocovalent adduct (white) and tricovalent adduct (gold) of $\mathbf{4}$ with R39. Oxygen atoms are colored red, nitrogen blue, boron pink, and chlorine green.

active serine. One of the boronate oxygen atoms lies in the oxyanion hole, and the other oxygen can mimic the hydrolytic water as it approaches the ester bond during deacylation, as proposed for the AmpC class C $\beta$-lactamase. ${ }^{34}$ The classical hydrogen bond between the ligand amide oxygen and the Asn300 side chain is preserved, but the amide nitrogen is somewhat too far from the Thr413 backbone oxygen to form a hydrogen bond.

We can now appreciate the very different positioning of the ligand amide group in the tricovalent complexes. The amide is twisted by $150^{\circ}$ with respect to its position in monocovalent complexes, and thus its hydrogen bonding to the protein has become completely reversed. In the tricovalent complex, the amide carbonyl group is hydrogen bonded to Thr413 NH, as noted above. In monocovalent complexes, including those of substrates, the amide carbonyl is directed toward N300 and the $\mathrm{NH}$ to the $\beta$-strand bordering the active site (Figure $3 \mathrm{e}, \mathrm{f}$ ). This dramatic change in position is brought about by movement of Ser49 $\mathrm{O} \gamma$ through rotation around Ser49 $\mathrm{C} \alpha-\mathrm{C} \beta$, and the consequent movement of the boron and its attached side chain "upward" in the active site to a position where it can coordinate to Ser298 and Lys410 (Figure 4). One might contemplate the design of new inhibitors on the basis of this newly revealed binding mode.

The chloro/nitro benzenes of compounds $\mathbf{4}$ and $\mathbf{5}$ are in a stacked $\pi$ interaction with the Tyr 147 phenyl group, but the orientation of the chlorobenzene is reversed when compared to the nitrobenzene. In monomers containing a monocovalent adduct, a sulfate ion is present, as seen in all ligand-free active sites of other R39 structures. This sulfate ion is close to the boronate oxygen atoms exactly where the carboxylate group of a peptide substrate binds. ${ }^{6}$

The observation of mono- and tricovalent adducts with $\mathbf{4}$ and 5 suggests that all of these amidomethylboronic acids first associate with the active-site serine and then react with the catalytically important residues Ser298 and Lys410, losing two oxygen atoms as water molecules in the process. The main difference between monomers $\mathrm{A}$ and $\mathrm{B}$ is the presence of a symmetry monomer close to the active site of monomer A. A slight opening of the active site upon acylation by an antibiotic seems to be a general property of PBPs ${ }^{35-37}$ and, also, possibly, on conversion of monocovalent to tricovalent boronate complexes. The presence in the crystal of a symmetric molecule close to the active site of monomers $\mathrm{A}$ and $\mathrm{D}$ could impair the opening of the active site. We have previously found different ligand conformations between both pairs of R39 monomers. ${ }^{6,38,39}$ In solution, of course, the enzyme is monomeric, and thus access to the active site should be unimpeded unless by conformational restriction within the monomer itself.

\section{DISCUSSION}

In contrast to many structures of boronic acid complexes with serine proteases and $\beta$-lactamases, the structures observed with $\mathrm{R} 39$ reveal unprecedented tricovalent complexes with compounds 1-5. We had previously observed monocovalent tetrahedral complexes of R39 with ethylboronic acids. ${ }^{6,18}$ Ethylboronic acids mimic a D-alanine residue, the natural amino acid that acylates the active serine of PBPs. In contrast, the methylboronic acids $1-5$ mimic a glycine rather than an alanine, and, as suggested ${ }^{40}$ and shown for the family of trypsin-like serine proteases, ${ }^{15}$ compounds resembling natural substrates make good transition-state analogues, whereas poorer analogues sometimes form unspecified unrelated adducts. This phenomenon has been extensively investigated with respect to acyclic substrates of DD-peptidases and $\beta$-lactamases. ${ }^{41-43}$ When the compound mimics a D-alanine, the additional methyl group is sequestered in a small hydrophobic pocket characteristic of PBPs, and the boronic acid cannot move further in the direction of the second serine to form di- or tricovalent adducts. Indeed, the observation of two different adducts with compounds 4 and 5 in the different monomers of the crystal structures suggests that the compound first associates with the active site serine and then rotates and moves close to the SXN serine and the KTG lysine, making bond formation and loss of two oxygen atoms, presumably as waters, possible.

The movement required to achieve the latter state is seen in Figure 4, which shows overlap between the two types of complexes with compound 4 . It is interesting to note that evidence of essentially the same type of motion of the activesite serine (rotation about the $\mathrm{C} \alpha-\mathrm{C} \beta$ single bond) has been obtained in the structure of a class $\mathrm{C} \beta$-lactamase, inhibited by an $\mathrm{O}$-aryloxycarbonyl hydroxamate, where the serine hydroxyl is cross-linked by a carbamate unit to the lysine corresponding to Lys410 of the R39 enzyme. ${ }^{44}$ Overlap of this $\beta$-lactamase active site with that of a classical monocovalent boronate-for example, that derived from $N$-(thienylacetyl)aminomethyl boronic acid ${ }^{45}$ shows that the boron-carbon distance between the adducts is ca. $4 \AA$; the distance between the boron atoms in Figure 4 is $3.4 \AA$. One can imagine the tricovalent boron adduct as the analogue of a tetrahedral intermediate generated on attack of Ser298 on a carbamate cross-link of Ser49 and Lys410. The tetrahedral boronate anion may be stabilized by a cationic Lys52, where the terminal nitrogen is 2.8 and $3.0 \AA$ from $\mathrm{O} \gamma$ of Ser49 and Ser298, respectively.

The usual interpretation of the biphasic curves observed in the reaction of methylboronic acids with $\beta$-lactamases consists of a simple formation of EI followed by slow modification to the tetrahedral adduct EI* ${ }^{16}$ Kettner and Shenvi suggested that all boronic acids rapidly form a tetrahedral complex with the active serine and that the slow binding phase would then be due to a conformational change of the enzyme to form a tighter complex. $^{30}$ In view of the structures described in this paper, however, and assuming that the tricovalent complexes observed 
in the crystal structures also form in solution, the slow phase of binding could, in principle, also result from further bonding of the boron with a catalytic residue of the active site after rapid formation of a monocovalent complex with Ser49. Note, however, that the observation of slow binding did not directly correlate with formation of tricovalent complexes, since the former was observed with 1, 2, and 5, while the latter were observed in all cases. Further, the biphasic kinetics observed with methylboronic acids were similar to those observed with ethylboronic acids and for which crystal structures did not show a tricovalent adduct. ${ }^{18}$ We therefore believe that the first phase observed in our experiments corresponds to formation of a simple Henri-Michaelislike complex. The second phase would then be associated with the acquisition of a tetrahedral conformation by the boron as it links to Ser49. Further bonding is not detectable, perhaps because the second adduct is in rapid equilibrium with the first one, and they are thus undistinguishable. Certainly, the $K_{\mathrm{i}}^{*}$ values of $\mathbf{1}$ determined from progress curves and after a preincubation of $60 \mathrm{~min}$ were very similar, and thus the formation of the tricovalent adduct is probably very rapid. Unfortunately, none of the adducts could be detected by mass spectrometry, even after trypsin digestion (data not shown), and this also suggests that the tricovalent adducts can undergo relatively facile dissociation under conditions obtaining in the mass spectrometer, as do the monocovalent adducts. The latter conclusion, of course, is also in accord with the reversible kinetics of inhibition. Thus, the model of inhibition of R39 by boronic acid should be modified to that described in Scheme 3.

The rapid formation of the noncovalent complex EI is followed by slow formation of the monocovalent tetragonal complex $\mathrm{EI}^{*}$ and rapid formation of the tricovalent tetragonal complex $\mathrm{EI}^{* *}$. The overall dissociation constant $K_{\mathrm{i}}^{* *}$ of this model is given by eq 7 :

$$
K_{\mathrm{i}} * * \frac{K_{\mathrm{i}} k_{-2}}{k_{+2}(1+K)+k_{-2}}=\frac{[\mathrm{E}][\mathrm{I}]}{[\mathrm{EI}]+\left[\mathrm{EI}^{*}\right]+\left[\mathrm{EI}^{* *}\right]}
$$

The ratio $k_{+2} / k_{-2}$ can be obtained from

$$
\frac{k_{+2}}{k_{-2}}=\left(\frac{K_{\mathrm{i}}}{K_{\mathrm{i}}^{* *}}-1\right) \frac{1}{1+K}
$$

Thus, for 1 , the overall dissociation constant $K_{\mathrm{i}}^{* *}$ can be described by eq 7 , and the ratio $k_{+2} / k_{-2}$ must be smaller than the observed ratio $k_{+2}(1+K) / k_{-2}=12$ observed for $\mathbf{1}$. Similarly, $k_{-2}$ must be larger than the apparent value $\left(0.003 \mathrm{~s}^{-1}\right)$. Thus, the observed dissociation rate of the inhibitory complex is significantly influenced by the formation of a tricovalent complex. In terms of chemistry, the formation of the tricovalent complex can be represented by Scheme 4 .

Ortho substituents on the phenyl group of the methylboronic acids improve the $K_{\mathrm{i}}$ of the unsubstituted compound 3. The improvement is weak in the case of 4 (chlorine) but strong with $\mathbf{1}$ (methoxy) and $\mathbf{5}\left(\mathrm{NO}_{2}\right)$. The absence of specific interactions of these groups in the monocovalent adducts does not provide a satisfactory explanation of the substituent effects, at least for compounds $\mathbf{4}$ and $\mathbf{5}$. In contrast, the interactions observed with the tricovalent adducts are in perfect agreement with the inhibitory properties of each compound. Particularly, the insertion of one $\mathrm{NO}_{2}$ oxygen in the oxyanion hole is determinant for the very low $K_{\mathrm{i}}=360 \mathrm{~nm}$ observed with $\mathbf{5}$. This is evidence that the
Scheme 3. Model of Inhibition of R39 by Boronic Acids ${ }^{a}$

$$
\mathrm{E}+\mathrm{I} \rightleftharpoons \mathrm{K}_{\mathrm{i}} \underset{k_{-2}}{\rightleftharpoons} \mathrm{EI}^{*} \stackrel{k_{2}}{\rightleftharpoons} \mathrm{EI}^{* *}
$$

${ }^{a} \mathrm{EI}$, noncovalent complex; $\mathrm{EI}^{*}$, monocovalent complex; $\mathrm{EI}^{* *}$, tricovalent complex.

Scheme 4. Rotation about the Ser $49 \mathrm{C} \alpha-\mathrm{C} \beta$ Bond (Curved Arrow) and Associated Movement of the Boronate (Figure 4)

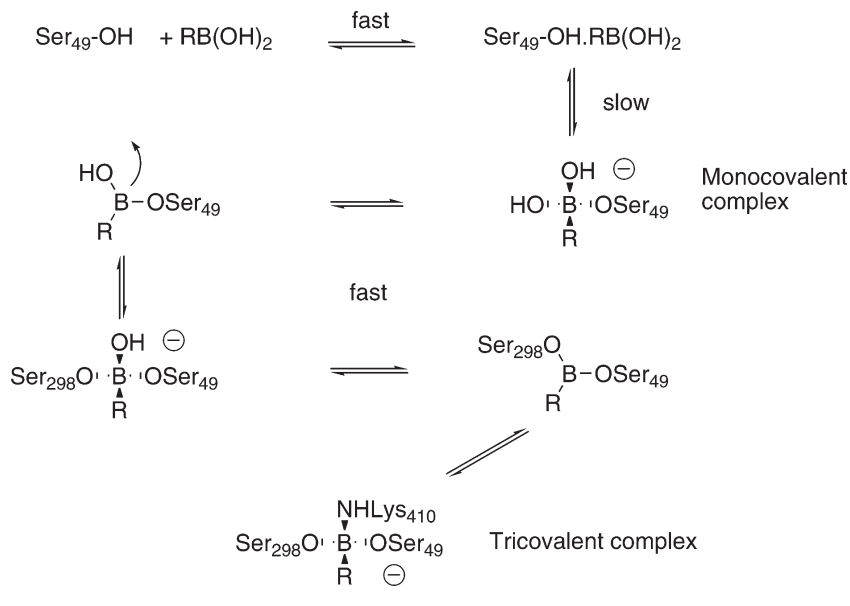

enzyme does, in fact, form the novel tricovalent boronate complexes in solution.

\section{CONCLUSION}

The boronates 1-5 inhibit the R39 DD-peptidase and form a mixture of monocovalent and tricovalent adducts at the active site, at least in the crystalline phase. The structures of the complexes of R39 with methylboronic acids described in this paper, and with ethylboronic acids reported in others, ${ }^{6,18}$ represent a remarkable demonstration that ethylboronic acids, resembling the natural substrate, are transition-state analogues, whereas methylboronic acids, lacking a fundamental feature of the natural substrate, can adopt an unexpected binding mode. Both types of boronic acids are good inhibitors of PBPs with interesting potential for development, but this previously unobserved tricovalent binding mode between a boronic acid and a serine hydrolase is a major aspect of boron chemistry that developers should be aware of, at least in cases where suitable additional ligands are available in the active site. The results obtained here suggest that boronic acid inhibitors may bind at least as tightly in these more highly coordinated complexes as in monocovalent transition,state analogue structures, and the correlation between the structures and inhibition constants reveals the importance of the tricovalent binding mode for PBP inhibition. Slower dissociation of the inhibitory complexes arising from formation of such structures would contribute to enhanced inhibitor "residence times". ${ }^{46}$

\section{ASSOCIATED CONTENT}

(5) Supporting Information. Complete ref 21. This material is available free of charge via the Internet at http://pubs.acs.org. 


\section{AUTHOR INFORMATION}

\section{Corresponding Author}

eric.sauvage@ulg.ac.be

\section{ACKNOWLEDGMENT}

We thank the staff of beamline BM30a at ESRF for assistance in X-ray data collection. This work was supported in part by the European Commission Sixth Framework Program grants LSMHCT-EUR-INTAFAR 2004-512138, by the Belgian Program on Interuniversity Poles of Attraction initiated by the Belgian State, Prime Minister's Office, Science Policy programming (IAP no. P6/19), by the Actions de Recherche Concertées (grant 03/08-297), by the Fonds de la Recherche Scientifique (IISN 4.4505.00, IISN 4.4509.09, FRFC 2.4.528.01.F, FRFC 9.4.538.03.F), and by the University of Liège (Fonds spéciaux, Crédit classique, 2099). F.K. is research associate of the FRS-FNRS. R.F.P. acknowledges support from the National Institutes of Health.

\section{REFERENCES}

(1) Sauvage, E.; Kerff, F.; Terrak, M.; Ayala, J. A.; Charlier, P. FEMS Microbiol. Rev. 2008, 32, 234-258.

(2) Macheboeuf, P.; Contreras-Martel, C.; Job, V.; Dideberg, O.; Dessen, A. FEMS Microbiol. Rev. 2006, 30, 673-691.

(3) Vollmer, W.; Blanot, D.; de Pedro, M. A. FEMS Microbiol. Rev. 2008, 32, 149-167.

(4) Macheboeuf, P.; Fischer, D. S.; Brown, T., Jr.; Zervosen, A.; Luxen, A.; Joris, B.; Dessen, A.; Schofield, C. J. Nat. Chem. Biol. 2007, $3,565-569$.

(5) Brown, T., Jr.; Charlier, P.; Herman, R.; Schofield, C. J.; Sauvage, E. J. Med. Chem. 2010, 53, 5890-5894.

(6) Dzhekieva, L.; Rocaboy, M.; Kerff, F.; Charlier, P.; Sauvage, E.; Pratt, R. F. Biochemistry 2010, 49, 6411-6419.

(7) Pechenov, A.; Stefanova, M. E.; Nicholas, R. A.; Peddi, S.; Gutheil, W. G. Biochemistry 2003, 42, 579-588.

(8) Inglis, S. R.; Zervosen, A.; Woon, E. C.; Gerards, T.; Teller, N.; Fischer, D. S.; Luxen, A.; Schofield, C. J. J. Med. Chem. 2009, 52, 6097-6106.

(9) Xu, Y.; Nakajima, Y.; Ito, K.; Zheng, H.; Oyama, H.; Heiser, U.; Hoffmann, T.; Gartner, U. T.; Demuth, H. U.; Yoshimoto, T. J. Mol. Biol. 2008, 375, 708-719.

(10) Bone, R.; Fujishige, A.; Kettner, C. A.; Agard, D. A. Biochemistry 1991, 30, 10388-10398.

(11) Tulinsky, A.; Blevins, R. A. J. Biol. Chem. 1987, 262, 7737-7743.

(12) Transue, T. R.; Gabel, S. A.; London, R. E. Bioconjugate Chem. 2006, 17, 300-308.

(13) Chen, Y.; Minasov, G.; Roth, T. A.; Prati, F.; Shoichet, B. K. J. Am. Chem. Soc. 2006, 128, 2970-2976.

(14) Takahashi, L. H.; Radhakrishnan, R; Rosenfield, R. E., Jr.; Meyer, E. F., Jr. Biochemistry 1989, 28, 7610-7617.

(15) Stoll, V. S.; Eger, B. T.; Hynes, R. C.; Martichonok, V.; Jones, J. B.; Pai, E. F. Biochemistry 1998, 37, 451-462.

(16) Crompton, I. E.; Cuthbert, B. K.; Lowe, G.; Waley, S. G. Biochem. J. 1988, 251, 453-459.

(17) Nicola, G.; Peddi, S.; Stefanova, M.; Nicholas, R. A.; Gutheil, W. G.; Davies, C. Biochemistry 2005, 44, 8207-8217.

(18) Woon, E. C. Y.; Zervosen, A.; Sauvage, E.; Simmons, K. J.; Zivec, M.; Inglis, S. R.; Fishwick, C. W. G.; Gobec, S.; Charlier, P.; Luxen, A.; Schofield, C. J. ACS Med. Chem. Lett. 2011, 2, 219-223.

(19) Adam, M.; Damblon, C.; Plaitin, B.; Christiaens, L.; Frere, J. M. Biochem. J. 1990, 270, 525-529.

(20) Jamin, M.; Adam, M.; Damblon, C.; Christiaens, L.; Frere, J. M. Biochem. J. 1991, 280 (Pt 2), 499-506.

(21) Granier, B.; et al. Methods Enzymol. 1994, 244, 249-266.
(22) De Meester, F.; Joris, B.; Reckinger, G.; Bellefroid-Bourguignon, C.; Frere, J. M.; Waley, S. G. Biochem. Pharmacol. 1987, 36, 2393-2403.

(23) Granier, B.; Duez, C.; Lepage, S.; Englebert, S.; Dusart, J.; Dideberg, O.; Van Beeumen, J.; Frère, J. M.; Ghuysen, J. M. Biochem. J. 1992, 282 (Pt 3), 781-788.

(24) Leslie, A. G. W. Crystallographic Computing 1991, 5, 50-61.

(25) CCP4 Acta Crystallogr. D: Biol. Crystallogr. 1994, 50, 760-763.

(26) Murshudov, G. N.; Vagin, A. A.; Dodson, E. J. Acta Crystallogr. D: Biol. Crystallogr. 1997, 53, 240-255.

(27) Painter, J.; Merritt, E. A. Acta Crystallogr. D: Biol. Crystallogr. 2006, 62, 439-450.

(28) Emsley, P.; Cowtan, K. Acta Crystallogr. D: Biol. Crystallogr. 2004, 60, 2126-2132.

(29) Copeland, R. A. In Enzymes: a practical introduction to structure, mechanism and data analysis; Copeland, R. A., Ed.; VCH Publishers, Inc.: New York, 1996; pp 225-261.

(30) Kettner, C. A.; Shenvi, A. B. J. Biol. Chem. 1984, 259, 15106-15114.

(31) Sauvage, E.; Duez, C.; Herman, R.; Kerff, F.; Petrella, S.; Anderson, J. W.; Adediran, S. A.; Pratt, R. F.; Frere, J. M.; Charlier, P. J. Mol. Biol. 2007, 371, 528-539.

(32) Kishida, H.; Unzai, S.; Roper, D. I.; Lloyd, A.; Park, S. Y.; Tame, J. R. Biochemistry 2006, 45, 783-792.

(33) Sauvage, E.; Herman, R.; Petrella, S.; Duez, C.; Bouillenne, F.; Frère, J. M.; Charlier, P. J. Biol. Chem. 2005, 280, 31249-31256.

(34) Wang, X.; Minasov, G.; Blazquez, J.; Caselli, E.; Prati, F.; Shoichet, B. K. Biochemistry 2003, 42, 8434-8444.

(35) Sainsbury, S.; Bird, L.; Rao, V.; Shepherd, S. M.; Stuart, D. I.; Hunter, W. N.; Owens, R. J.; Ren, J. J. Mol. Biol. 2010, 405, 173-184.

(36) Macheboeuf, P.; Di Guilmi, A. M.; Job, V.; Vernet, T.; Dideberg, O.; Dessen, A. Proc. Natl. Acad. Sci. U.S.A. 2005, 102, 577-582.

(37) Lim, D.; Strynadka, N. C. Nat. Struct. Biol. 2002, 9, 870-876.

(38) Sauvage, E.; Powell, A. J.; Heilemann, J.; Josephine, H. R.; Charlier, P.; Davies, C.; Pratt, R. F. J. Mol. Biol. 2008, 381, 383-393.

(39) Sauvage, E.; Zervosen, A.; Dive, G.; Herman, R.; Amoroso, A.; Joris, B.; Fonze, E.; Pratt, R. F.; Luxen, A.; Charlier, P.; Kerff, F. J. Am. Chem. Soc. 2009, 131, 15262-15269.

(40) Tsilikounas, E.; Kettner, C. A.; Bachovchin, W. W. Biochemistry 1992, 31, 12839-12846.

(41) Bernstein, N. J.; Pratt, R. F. Biochemistry 1999, 38, 10499-10510.

(42) Adediran, S. A.; Zhang, Z.; Nukaga, M.; Palzkill, T.; Pratt, R. F. Biochemistry 2005, 44, 7543-7552.

(43) Adediran, S. A.; Cabaret, D.; Flavell, R. R.; Sammons, J. A.; Wakselman, M.; Pratt, R. F. Bioorg. Med. Chem. 2006, 14, 7023-7033.

(44) Wyrembak, P. N.; Babaoglu, K.; Pelto, R. B.; Shoichet, B. K.; Pratt, R. F. J. Am. Chem. Soc. 2007, 129, 9548-9549.

(45) Caselli, E.; Powers, R. A.; Blasczcak, L. C.; Wu, C. Y.; Prati, F.; Shoichet, B. K. Chem. Biol. 2001, 8, 17-31.

(46) Copeland, R. A.; Pompliano, D. L.; Meek, T. D. Nat. Rev. Drug Discov. 2006, 5, 730-739. 